\title{
Mechanisms of Nucleosome Dynamics In Vivo
}

\author{
Steven Henikoff \\ Howard Hughes Medical Institute, Fred Hutchinson Cancer Research Center, Seattle, Washington 98109 \\ Correspondence: steveh@fredhutch.org
}

\begin{abstract}
Nucleosomes function to tightly package DNA into chromosomes, but the nucleosomal landscape becomes disrupted during active processes such as replication, transcription, and repair. The realization that many proteins responsible for chromatin regulation are frequently mutated in cancer has drawn attention to chromatin dynamics; however, the basic mechanisms whereby nucleosomes are disrupted and reassembled is incompletely understood. Here, I present an overview of chromatin dynamics as has been elucidated in model organisms, in which our understanding is most advanced. A basic understanding of chromatin dynamics during normal developmental processes can provide the context for understanding how this machinery can go awry during oncogenesis.
\end{abstract}

Cequencing of tumor DNA has uncovered Omutations and rearrangements of wellknown tumor suppressor genes and oncogenes in a wide variety of human cancers, confirming much of what had been learned from decades of cancer research (Vogelstein et al. 2013). Such genetic insights verify the long-held assumption that cancer is not a single disease, but rather many diseases. Nevertheless, tumor DNA sequencing has also revealed a surprising number of likely driver mutations in a variety of shared chromatin components, sometimes seen in cancers that otherwise have little else in common (Pon and Marra 2015). From this epigenetic perspective, cancer might be viewed as a complex syndrome in which normal mechanisms that maintain chromatin homeostasis become disrupted in such a way that they may be subject to selection for uncontrolled proliferation. On the one hand, finding a chromatin basis for so many cancers has led to the hope for therapeutic intervention to reverse the cancer phenotype, and other reviews discuss progress on these fronts. On the other hand, the complexity of the chromatin landscape makes it difficult to explain a wide variety of observations, some of which almost seem to lack a rational basis. For example, a histone modification that is present in all eukaryotic life, H3K79 methylation, can be essentially eliminated in the hematopoietic system in which it efficiently kills leukemia cells but has little effect on normal stem/progenitor cells (Daigle et al. 2011). Another example is a lysine-to-methionine mutation in the histone $\mathrm{H} 3$ tail that promotes a highly aggressive tumor when it occurs in a specific site in a child's brain (Wu et al. 2012), but a nearby mutation in the same histone tail results in a benign tumor when it occurs in a specific bone-forming cell of an adult (Behjati et al. 2013). To make sense of these and other issues raised by the discovery of mutations in chromatin regulators, we need

Editors: Scott A. Armstrong, Steven Henikoff, and Christopher R. Vakoc

Additional Perspectives on Chromatin Deregulation in Cancer available at www.perspectivesinmedicine.org

Copyright (C) 2016 Cold Spring Harbor Laboratory Press; all rights reserved; doi: 10.1101/cshperspect.a026666

Cite this article as Cold Spring Harb Perspect Med 2016;6:a026666 


\section{S. Henikoff}

to consider the molecular and developmental context in which the various components of the chromatin machinery normally function.

Here, I will survey chromatin dynamics during normal processes, focusing on those proteins and complexes that are most frequently mutated in cancer (Fig. 1). Most of our understanding of these processes comes from studies in model organisms, in which powerful genetic, biochemical, and genomic tools have long been applied. With the advent of new technologies, such as genome editing (Laufer and Singh 2015) and live super-resolution microscopy (Liu et al. 2015), the impact of traditional genetic studies of model organisms on understanding cancer genetics and epigenetics is likely to continue.

\section{DISRUPTING AND REMODELING NUCLEOSOMES}

The tight wrapping of DNA around the octameric core of nucleosomes requires their mobilization or eviction to make the DNA accessible for replication, transcription, and repair to occur. Nucleosomes are completely disrupted every cell cycle before the DNA duplex passes through the replicative helicase, which separates the Watson and Crick strands for templated DNA synthesis, followed by reassembly on leading and lagging strands (Ramachandran and Henikoff 2015). Nucleosomes are also disrupted during passage of RNA polymerases, although the high density of nucleosomes over all but the most actively transcribed genes (Weintraub and Groudine 1976) implies that nucleosome disruption and reassembly during transcription must be very efficient. Considering that a nucleosome is an impenetrable barrier to the large RNA polymerase II (RNAPII) holoenzyme complex in vitro, how it can transcribe through a nucleosome in vivo remains incompletely understood (Teves et al. 2014). Another dynamic process that disrupts nucleosomes is remodeling by a class of DNA translocases related to the yeast switch-2/sucrose nonfermenting-2 (SWI2/SNF2) ATPase (Clapier and Cairns 2009).

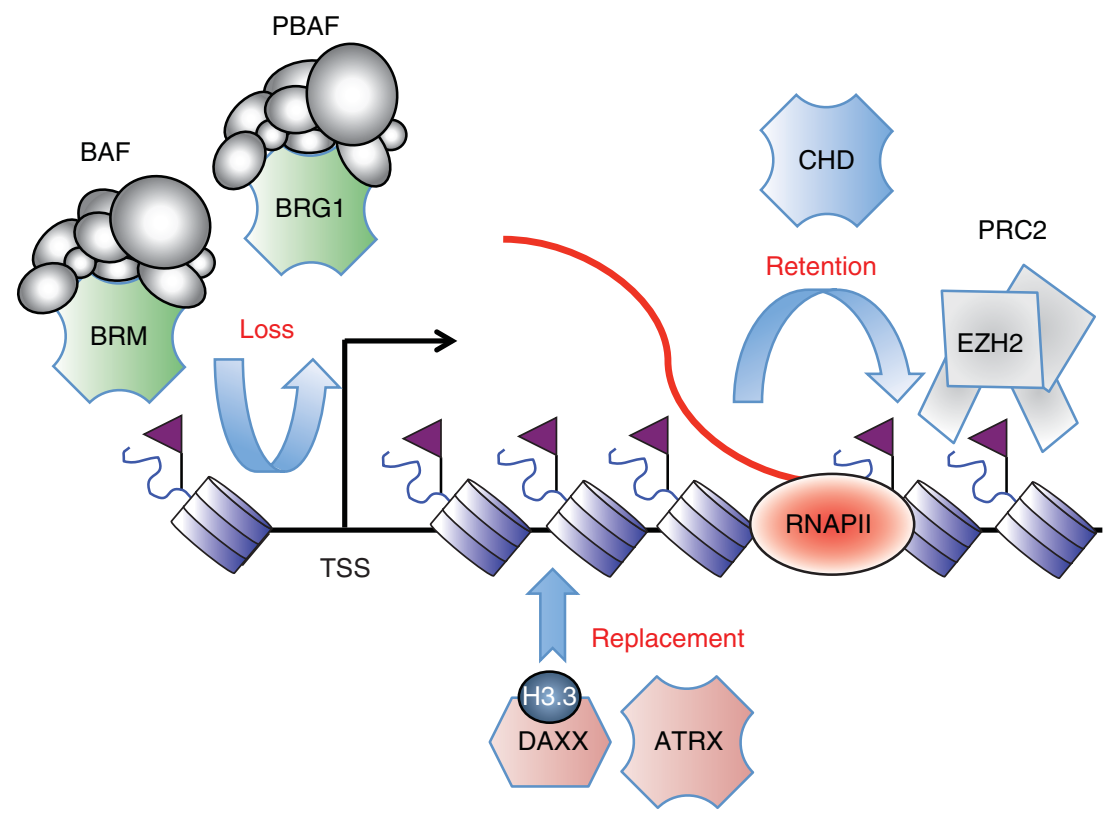

Figure 1. Regulators of chromatin dynamics implicated in cancer. (P)BAF complexes catalyze nucleosome sliding and/or eviction, ATRX and DAXX promote replacement with H3.3 nucleosomes, CHD ATPases facilitate transcriptional elongation, and the PRC2 complex methylates the $\mathrm{H} 3$ amino-terminal tail at lysine-27 to stabilize nucleosomes. 
Phylogenetic analysis of human and yeast members of the SWI/SNF superfamily reveals 11 distinct subfamilies, all with at least one human and one yeast member (Fig. 2). Four subfamilies, RAD54, RAD26, RAD16, and FUN30, are DNA translocases that function in DNA repair and/or recombination (Chen et al. 2012; Costelloe et al. 2012; Hinz and Czaja 2015; Li 2015; Waters et al. 2015), and MOT1 is dedicated to regulate TATA-binding protein by removing it from high-affinity sites (Wollmann et al. 2011; Zentner and Henikoff 2013). The other six subfamilies use nucleosomes as substrates for remodeling, and except for IRC5, which is as-yet uncharacterized, all have been shown to perform distinct nucleosome mobilization reactions. CHD (chromo-helicase-DNA-binding), ISWI (imitation switch), and SNF2 subfamily translocases slide histone cores along the DNA duplex. Biochemical characterization of SNF2 and ISWI remodelers in yeast and Drosophila led to the realization that these different phylogenetic subgroups have rather different actions on nucleosomes: SNF2-class remodelers disrupt nucleosomes to facilitate activation, ISWI-class remodelers reposition and regularly space nucleosomes, and CHD-class remodelers help RNAPII transcribe through a nucleosome. These differences led to the realization that nucleosome dynam-

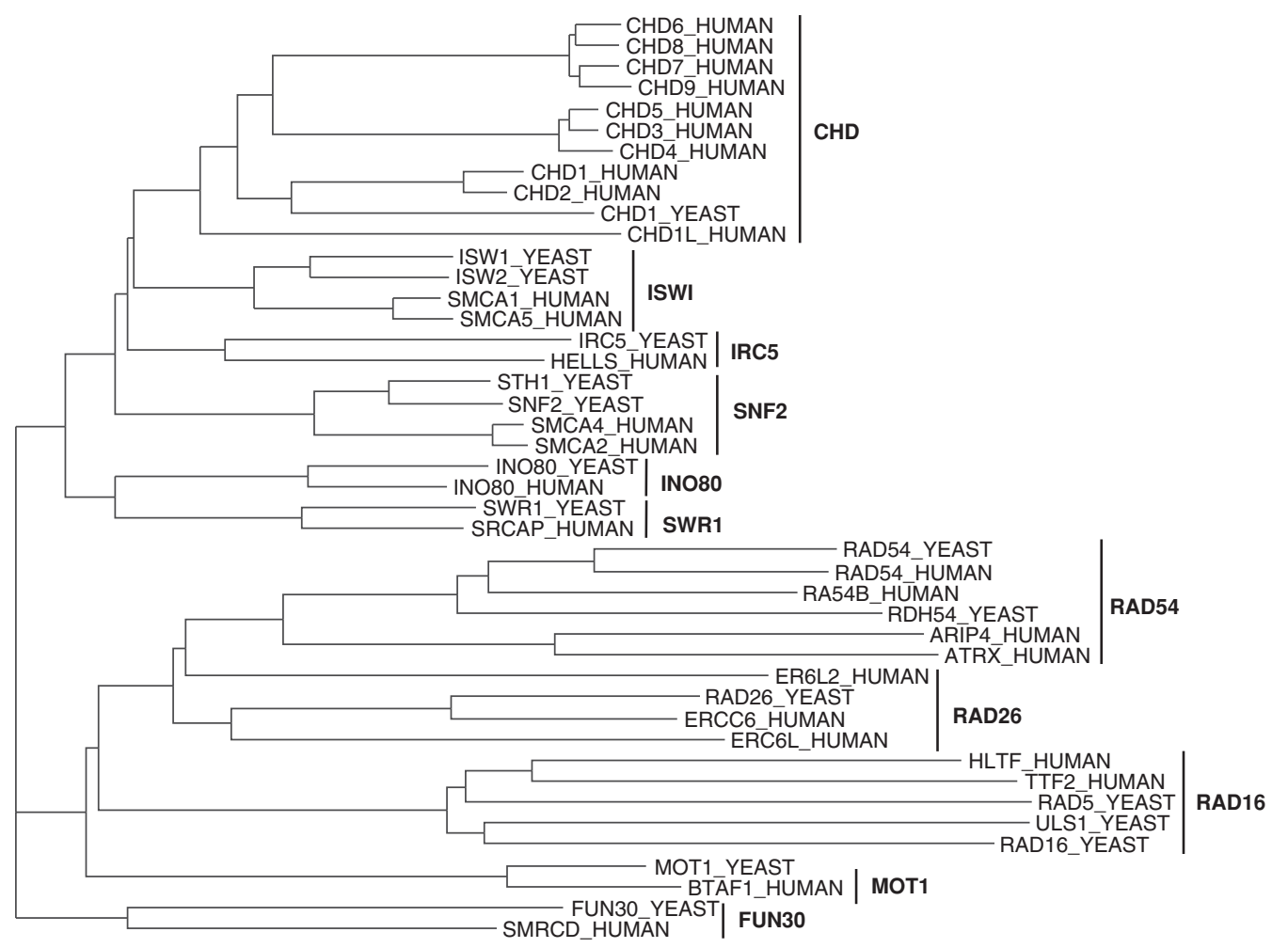

Figure 2. Phylogeny of SWI/SNF ATPase superfamily members in humans and yeast. Dendrogram shows that each subfamily is represented in both species. For example, the SNF2 subfamily includes the ATPase subunit for yeast RSC (Sth1) and SWI/SNF (Snf2) and for PBAF (SMARCA4=BRG1) and BAF (SMARCA2=BRM). For consistency, the SWISS-PROT name for each protein is used in the phylogeny. To obtain human and yeast members of the superfamily, ATRX_HUMAN was used as query versus human- and yeast-annotated SWISSPROT amino acid sequences. Multiple alignment was performed using MAFFT with defaults, pruning with the MaxAlin option to maximize alignment quality, and a neighbor-joining tree was constructed using all 364 gapfree residues with the JTT amino acid substitution matrix. Ten distinct subfamilies were identified, each with at least one human and one yeast protein. 


\section{S. Henikoff}

ics can have a profound effect on gene expression.

Biochemical characterization of nucleosome remodelers has also distinguished them based on differences in subunit composition. Whereas the yeast Chd1 remodeler is a single subunit enzyme, Swr1 and Ino80 ATPases are each part of 14-subunit complexes. The SWR1 complex is dedicated to replacing canonical histone $\mathrm{H} 2 \mathrm{~A}$ with the H2A.Z histone variant, and the INO80 complex is capable of performing the reverse reaction (Watanabe and Peterson 2010). It is thought that these opposing reactions constitute a futile cycle in which $\mathrm{H} 2 \mathrm{~A} / \mathrm{H} 2 \mathrm{~B}$ dimers, which flank the central $(\mathrm{H} 3 / \mathrm{H} 4)_{2}$ tetramer in the nucleosome, are dynamically exchanged during transcription. Dynamic exchange of histone dimers is promoted by acetylation of histone H3K56 (Watanabe et al. 2013), an example of how chromatin remodeling, histone variants, and histone modifications can work together to dynamically maintain the chromatin landscape.

In the budding yeast, there are two SNF2class remodeler complexes, RSC and SWI/SNF (Clapier and Cairns 2009). RSC is abundant, broadly distributed, and essential, whereas SWI/SNF is much less abundant than RSC and is nonessential. RSC is similar to the Polybromo (PBAF) complex, in having multiple subunits with bromodomains, a class of modules that bind to acetylated histone tails. In fact, eight of the 15 bromodomains encoded in the yeast genome are present in the RSC complex. SNF2 is similar to the BRM subunit of the BAF complex, which in mammals shares most of its subunits with PBAF. Yeast RSC and SWI/SNF have different catalytic subunits (Sth1 for RSC and Snf2 for SWI/SNF), and mammalian PBAF and BAF also have different catalytic subunits (BRG1 for PBAF and BRM for BAF), which suggest that the two complexes play different chromatin remodeling roles. However, Drosophila has only a single SNF2-class catalytic subunit, BRM, which suggests that these complexes are redundant at the basic biochemical level.

Most (P)BAF cancer mutations are found in subunits shared between the two complexes, which suggests that some common feature of SWI/SNF-class remodelers is responsible for chromatin alterations characteristic of the oncogenic state (Kadoch et al. 2013). Insofar as $>20 \%$ of all human cancers are found to harbor loss-of-function mutations in P-BAF or BAF complex subunits, elucidating the molecular mechanism of SNF2-class remodeling is crucial for understanding oncogenesis in these cancers.

The yeast RSC complex has been intensively studied both biochemically and structurally. RSC is several-fold larger than the nucleosome, and RSC is a powerful DNA translocase that hydrolyzes 3 ATPs per base pair with a step size of $\sim 1$ base pair (Eastlund et al. 2013). A model for RSC action is that it engulfs and unwraps the nucleosome up to the dyad axis by electrostatic attraction of DNA to its inner surface (Chaban et al. 2008; Lorch et al. 2010). Then Sth1 hydrolyzes ATP in a power stroke that releases the remaining histone-DNA contacts to pump through DNA, resulting in directional sliding of the histone octamer along DNA. This model is supported by the in vivo observation that RSC-bound nucleosomes are unwrapped up to the dyad axis, a putative RSC/ nucleosome remodeling intermediate (Ramachandran et al. 2015). In some circumstances, RSC can evict a nucleosome core from the DNA entirely (Lorch et al. 2006), and the evidence that RSC facilitates the loss and replacement (turnover) of nucleosomes in vivo (Dion et al. 2007; Hartley and Madhani 2009) is consistent with eviction being an extreme manifestation of sliding in the context of a chromatin fiber that is densely packed with nucleosomes. These sliding and eviction capabilities of RSC can account for the well-established role of RSC in the generation of nucleosome-depleted regions genomewide in vivo (Ganguli et al. 2014), which is a prerequisite for formation of a preinitiation complex that recruits RNAPII. We might view the SNF2-class remodelers as machines that clear nucleosomes from promoters so that transcription can initiate.

It is probable that Drosophila Brahma, the only SNF2-class remodeler in the fly genome (Tamkun et al. 1992), and mammalian PBAF and BAF complexes (Wilson and Roberts 2011) are likewise responsible for clearing nucleo- 
somes from promoters. Moreover, the evidence that enhancers are also sites of enhancer RNA (eRNA) transcriptional initiation (Lai and Shiekhattar 2014) suggests that PBAF and BAF may serve a similar function at cis-regulatory sites in general. Thus, the central role of SNF2-class remodelers in transcription initiation throughout the genome may have made cells especially vulnerable to transcriptional misregulation when their function is altered by loss of a regulatory subunit (Kim and Roberts 2014). The fact that some individual subunits have been implicated in cell-type-specific functions of PBAF/BAF complexes (Hargreaves and Crabtree 2011) fits with the notion that cancer loss-of-function mutations in various subunits result in cell-type-specific misregulation of this powerful nucleosome clearing apparatus.

Tumor DNA sequencing has also led to the identification of driver mutations in ATRX ( $\alpha$-thalassaemia/mental retardation $\mathrm{X}$-linked) (Picketts et al. 1996), which belongs to the RAD54 branch of the SWI/SNF superfamily of DNA translocases (Fig. 2). Germline homozygous loss-of-function ATRX mutations cause ATRX syndrome, in which an $\alpha$-thalassaemia is associated with improper chromatin packaging of the $\alpha$-globin CpG island promoter (Law et al. 2010). Little was understood about the mechanism of action of ATRX syndrome until tumor sequencing revealed that mutations in ATRX and in the associated DAXX histone chaperone are mutually exclusive driver mutations in $\sim 4 \%$ of human cancers (Heaphy et al. 2011a; Jiao et al. 2011). Indeed, the study of these cancer mutations led to elucidation of the ATRX/ DAXX nucleosome assembly pathway, a reversal of the usual paradigm in which basic science advances help to inform the mechanism of cancer drivers.

The Rad54 DNA translocase does not remodel nucleosomes, but studies of the Rad54related ATRX ortholog in Drosophila, XNP, have suggested that ATRX translocation prepares the DNA substrate for assembly of histone H3.3 nucleosomes (Schneiderman et al. 2009, 2012). DAXX is a histone chaperone that is dedicated to the assembly of nucleosomes containing the histone $\mathrm{H3} 3$.3 variant, by depositing successive dimers of $\mathrm{H} 3.3$ / $\mathrm{H} 4$ to form the central tetramer of octameric $(\mathrm{H} 2 \mathrm{~A} / \mathrm{H} 2 \mathrm{~B} / \mathrm{H} 3.3 / \mathrm{H} 4)_{2}$ nucleosomes (Ray-Gallet et al. 2002; Drane et al. 2010; Lewis et al. 2010; Elsasser et al. 2012). The normal function of the ATRX-DAXX-H3.3 nucleosome assembly pathway is thought to be filling of gaps in the nucleosome landscape at sites where periodicities and base-compositional biases disfavor tight wrapping of nucleosomes (Fig. 2) (Schneiderman et al. 2009).

A unique feature of ATRX and DAXX mutations is that they are hallmarks of the alternative lengthening of telomeres (ALT) phenotype (Lovejoy et al. 2012). ALT is recognized as a less frequent alternative to telomerase activation that cancer cells can adopt to escape senescence, which likely accounts for the occurrence of ALT in a wide variety of cancers. ALT is readily detected using fluorescence in situ hybridization (FISH) with telomere DNA probes, seen as sporadic cells with extraordinarily long telomeres (Heaphy et al. 2011b). The precise mechanism whereby mutations in the H3.3 assembly pathway lead to the ALT phenotype has not been fully elucidated. However, a recent finding that CHK1-mediated phosphorylation of H3.3 serine-31, one of only four $\mathrm{H} 3.3$ residues not found in replication-coupled (RC) variants $\mathrm{H} 3.1$ and H3.2, is essential for the full ALT phenotype (Chang et al. 2015) raises the possibility that CHK1 kinase inhibitors might be used to specifically kill cancer cells driven by ATRX and DAXX mutations. ALT also sensitizes cells to ATR (ataxia telangiectasia and Rad3-related) protein kinase inhibitors (Flynn et al. 2015), presumably by reducing phosphorylation of histone H2A.X as part of the DNA damage response pathway. Thus, histone variant phosphorylation promises to be a more general regulatory paradigm that might be exploited in treating ALT-associated cancers.

\section{MODIFYING NUCLEOSOMES}

The surface of the nucleosome core and its histone tails are rich in basic residues that neutralize the strong negative charges of the DNA phosphate backbone. Whereas core surface ar- 


\section{S. Henikoff}

ginine side chains sit in the DNA minor groove to tightly wrap the duplex around the particle, lysines on the tails can undergo dynamic cycles of acetylation and deacetylation that neutralize and recharge the tails to facilitate active processes such as transcription (Wolffe 1992; Waterborg 2002). Charge neutralization is thus a universal function of acetylation. In addition, the acetyltransferases and deacetylases that mediate this process are often mutated or aberrantly expressed in cancer, and histone deacetylase (HDAC) inhibitors have been widely used in cancer chemotherapy (Ma et al. 2016). But whether histones themselves are the therapeutic targets of HDAC inhibitors is unclear, in that many nonhistone proteins, including metabolic enzymes, are regulated by acetylation (Downey and Baetz 2015). Furthermore, it has been proposed that a bulk function of histone tail acetylation is $\mathrm{pH}$ homeostasis, in which release of acetate and export from the cell reduces intracellular pH (McBrian et al. 2013). These observations complicate interpretation of HDAC inhibition studies.

Histone lysines also undergo cycles of methylation and demethylation, although on much slower time scales from cycles of acetylation and deacetylation. Whereas the half-life of an acetyl on a histone might be measured in seconds or minutes, the average methyl has a half-life that is nearly the same as the histone (Waterborg 1993, 2002). From a kinetic perspective, the stability of histone methylation makes it a strong candidate for a modification that perpetuates chromatin memory, one that can be selectively removed to allow for gene expression to occur. For example, $\sim 70 \%$ of H3K27 lysines in the Drosophila genome are dimethylated by Polycomb repressive complex 2 (PRC2), which serves to prevent global unscheduled transcription (Lee et al. 2015), but only H3K27me3 is associated with regulated developmental silencing (Schwartz and Pirrotta 2013). To selectively derepress a gene without removing the histone, the UTX H3K27-specific demethylase may be targeted to demethylate $\mathrm{H} 3 \mathrm{~K} 27$ residues down to di- and monomethylation (Agger et al. 2007).

It is often asserted that histone methylation is "epigenetic" based on the analogy to DNA methylation (Ptashne 2007). DNA methyls are inherited by the action of the Dnmt1 DNA methyltransferase, which faithfully methylates the cytosine of a CG dinucleotide on the newly replicated strand at the replication fork, but only when the parental cytosine on the opposite strand is methylated (Bestor 1996). However, unlike modifications of DNA, all DNA-binding proteins are removed in advance of DNA polymerization by the action of the replicative helicase. Therefore, all histones, whether old or new, must be deposited de novo on leading and lagging strands behind the replication fork. This means that inheritance of a modification cannot be assumed, and without direct evidence, it remains formally possible that all histone modifications are reestablished de novo as are the nucleosomes that they modify. Direct evidence for inheritance of a histone modification has been obtained in the case of the Caenorhabditis elegans germline, in which loss of the PRC2 complex that methylates $\mathrm{H} 3 \mathrm{~K} 27$ nevertheless allows for retention of $\mathrm{H} 3 \mathrm{~K} 27 \mathrm{me} 3$ (Gaydos et al. 2014). Just how this feat of legerdemain at the replication fork is accomplished remains the subject of speculation (Ramachandran and Henikoff 2015).

EZH2 (enhancer-of-zeste homolog 2), the catalytic component of the mammalian PRC2 complex, is up-regulated in many cancers, and effective and safe inhibition of EZH2 is a major goal of pharmacological research (Koppens and van Lohuizen 2015). Other histone modifications, including acetylation and $\mathrm{H} 3 \mathrm{~K} 4, \mathrm{H} 3 \mathrm{~K} 36$, and H3K79 methylation, are associated with the transcriptionally active state, and some of the enzymes responsible for these modifications have been implicated in driving tumorigenesis (Bernt et al. 2011; Colon-Bolea and Crespo 2014; Riedel et al. 2015). From the perspective of cancer therapeutics, these activation-associated modifications represent attractive targets, insofar as inhibition of the enzymes that are involved in the gene activation process might be expected to down-regulate oncogenes that are aberrantly expressed in cancer. However, from a mechanistic perspective, possible roles of these "activating" modifications in mediating gene expression is more poorly understood than in 
the case of "silencing" modifications. Specifically, the high-affinity binding of histone binder ("reader") proteins, including Polycomb to $\mathrm{H} 3 \mathrm{~K} 27 \mathrm{me} 3$, and heterochromatin-associated protein 1 ( $\mathrm{HP}-1)$ to $\mathrm{H} 3 \mathrm{~K} 9 \mathrm{me} 2$ and $\mathrm{H} 3 \mathrm{~K} 9 \mathrm{me} 3$, helps to immobilize nucleosomes (Canzio et al. 2011; Schwartz and Pirrotta 2013). Reducing nucleosome dynamics likely impedes transcriptional activation, which requires accessible DNA for transcription factors to bind. In contrast, histone-modifying enzymes that are enriched at active genes most likely act during the dynamic process of transcription, being associated with the carboxy-terminal domain of the large subunit of RNA polymerase II (Henikoff and Shilatifard 2011). Thus, these enzymes act on nucleosomes as they are being disrupted and reassembled by the machinery that moves a denaturation bubble forward as it adds RNA bases onto the growing RNA chain. As is the case for disruption of nucleosomes by replication fork passage, our understanding of nucleosome dynamics during transcription is far from complete.

An additional uncertainty in understanding the role of histone modifications in cancer is whether the modification of histones, as opposed to nonhistone proteins, is relevant to the cancer phenotype (Carlson and Gozani 2016). Moreover, cancer cell lines in which overexpression of the NSD2 SET domain-containing histone methyltransferase causes increases in H3K36 methylation also causes decreases in H3K27 methylation (Popovic et al. 2014). This anticorrelation could result from interference along the $\mathrm{H} 3$ tail, but might also be an indirect effect. As lysine methylation is a common regulatory modification of many proteins, including transcription factors (Levy et al. 2011; Carlson et al. 2015), it is also possible that the therapeutic target of NSD2 is instead a nonhistone protein, in which case these changes that occur on the lysine tail represent collateral damage with no physiological consequences. It should be kept in mind that calling these enzymes "histone" methyltransferases, demethylases, etc., does not necessarily reflect their in vivo activities, but rather the historical fact that the lysine richness of histones made them convenient substrates for use in biochemical purification. To avoid this misunderstanding, the accepted nomenclature for what was previously referred to as histone methyltransferases (HMTs) has been changed to "lysine" methyltransferases (KMTs) and so on for other chromatin-modifying enzymes (Allis et al. 2007).

A similar uncertainty as to physiological function applies to histone reader proteins, which bind their modified substrates sometimes with nanomolar affinities. In the case of Polycomb and HP-1, there is both genetic and biochemical evidence that their action includes preferential binding of methylated H3K27 and H3K9 lysines, respectively, including similar phenotypes for the orthologous modifying enzymes and reader proteins in Drosophila (Schotta et al. 2002; Schwartz and Pirrotta 2013). However, in other cases, the situation is ambiguous, for example, whether the various bromodomains found to preferentially bind acetylated histone tails actually bind these tails in vivo, and if they do, whether or not the binding is simply a consequence of the extraordinarily high concentration of acetylated histone lysines in the nucleus (Shi and Vakoc 2014). The development of reader protein inhibitors (Filippakopoulos et al. 2010) and ascertainment of their safety in the clinic will likely benefit from a better understanding of their physiologically relevant targets.

\section{REPLACING CANONICAL HISTONES WITH VARIANTS}

Most histones are rapidly synthesized from multicopy genes during $S$ phase by specialized mRNA processing machineries and are deposited into nucleosomes immediately behind the replication fork (Marzluff et al. 2002). Other histones are synthesized throughout the cell cycle from ordinary genes and are incorporated into nucleosomes by dedicated histone chaperones (Henikoff and Smith 2015). These replication-independent (RI) histones include the aforementioned H3.3 histone variant, which is the exclusive substrate for RI assembly on chromosome arms, as are H3.1 and H3.2 the exclusive substrates for RC nucleosome assembly 


\section{S. Henikoff}

A

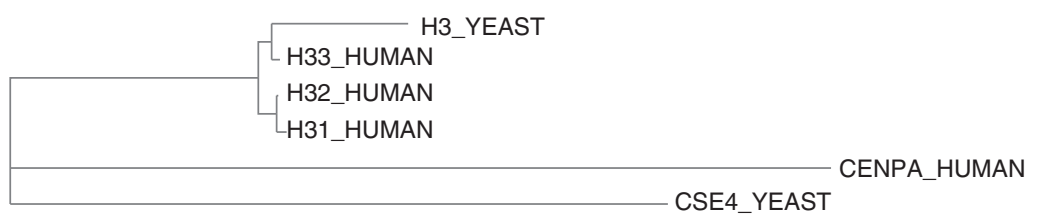

B

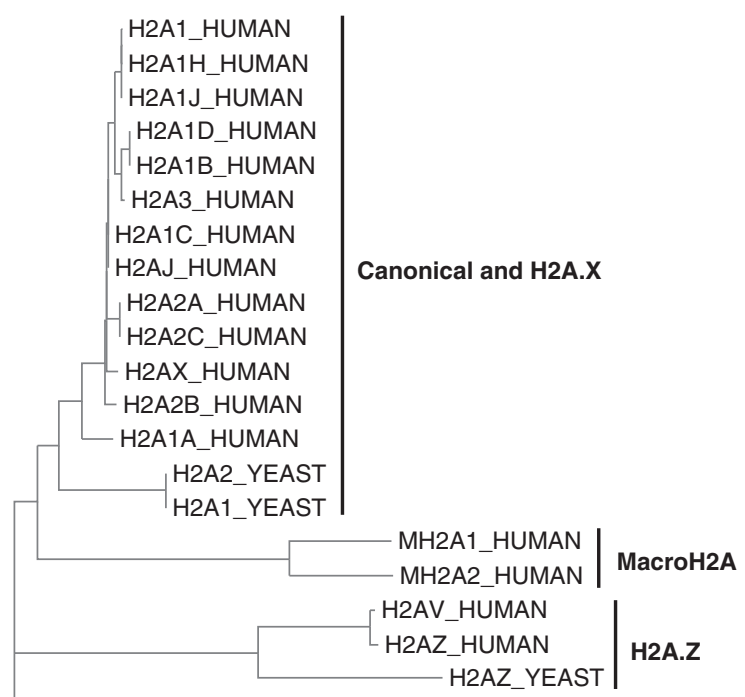

Figure 3. Phylogenies of histone variants in humans and yeast. All $\mathrm{H} 3(A)$, and $\mathrm{H} 2 \mathrm{~A}(B)$ variants annotated in SWISS-PROT are included (see the legend to Fig. 1 for details).

(Fig. 3A). Another notable histone variant is cenH3 (called CENP-A in mammals), which is the defining component of nucleosomes that form the chromatin foundation for the centromere. Most other RI histones are variants of $\mathrm{H} 2 \mathrm{~A}$, including H2A.X, which is rapidly phosphorylated on a carboxy-terminal serine when DNA breaks in its vicinity, H2A.Z, which acts to weaken the nucleosome barrier to transcription, and macroH2A, H2A.B, and H2A.L, which are mammalian histone variants of uncertain function (Fig. 3B). The substitution of a histone variant for a canonical histone represents a profound change in nucleosome properties that can potentially affect nucleosome dynamics. For example, H2A.Z has a very different "docking domain" from $\mathrm{H} 2 \mathrm{~A}$, which contacts $\mathrm{H} 3 / \mathrm{H} 4$ in the nucleosome core and can affect its stability (Suto et al. 2000). Also, H2A.B forms a "short wrapper" nucleosome core that makes fewer contacts with DNA, potentially reducing stability (Bao et al. 2004). macroH2A, which is enriched in silent chromatin, is unique among core histones in having a globular domain of uncertain function that protrudes from the canonical core (Costanzi and Pehrson 1998).

Until recently, histone variants have received much less attention in the cancer and chromatin field than histone modifications, which are catalyzed by many different modifying and demodifying enzymes and bound by reader proteins that provide attractive targets for small molecule drug development (Copeland et al. 2010; Filippakopoulos et al. 2010). However, tumor DNA sequencing studies have revealed unexpected roles for histone variants in promoting tumorigenesis. Specific driver mutations have been discovered in H3.3 genes that are characteristic of specific cancer types to an extraordi- 
nary degree: H3.3K27M mutations are found in most diffuse midline gliomas (DIPGs) and many pediatric glioblastomas ( Wu et al. 2012), and $\mathrm{H} 3.3 \mathrm{~K} 36 \mathrm{M}$ mutations are driver mutations in nearly all chondroblastomas and H3.3G34W/L mutations in nearly all giant cell tumors of bone (Behjati et al. 2013). Whereas DIPGs are highly aggressive pediatric cancers, the bone tumors are less invasive and sometimes benign, and are also found in adults. All are likely gain-of-function mutations in that these tumors also express normal H3.3 copies. For example, in mammalian cells, expression of the H3.3K27M protein contributes to neoplastic transformation (Funato et al. 2014), and a similar neoplastic effect is seen for $\mathrm{H} 3 \mathrm{~K} 36 \mathrm{M} / \mathrm{I}$ mutations found in chondroblastomas ( $\mathrm{Lu}$ et al. 2016). A gain-of-function interpretation of these phenotypes is also supported by studies in Drosophila, whereby introduction of the K27M mutation in an H3.3 transgene results in dominant Polycomb phenotypes, consistent with methionine-27 titrating the PRC2 complex (Lewis et al. 2013; Herz et al. 2014). Indeed, elucidation of the structure of a PRC2 complex homolog binding a histone H3K27M aminoterminal tail peptide shows that the mutation results in occlusion of the enzymatic active site by the neighboring H3R26 arginine side chain (Jiao and Liu 2015). Another candidate for mediating at least some of these cancers is the ZMYND11 zinc-finger tumor suppressor protein that specifically binds to both lysine-36 and (H3.3-specific) serine-31 (Wen et al. 2014).

Tumor sequencing and gene expression studies have also drawn attention to the possibility that RI nucleosome assembly pathway components might be potential drug targets, for example, the inhibition of the CHK1 and ATR kinases, which preferentially phosphorylate H3.3 and H2A.X in cancer cells (Chang et al. 2015). In the case of H2A.Z, overexpression is associated with poor prognosis in $\mathrm{ER} \alpha$ breast cancer (Hua et al. 2008), and hyperacetylation of H2A.Z is a feature of deregulated promoters in prostate cancer (Valdes-Mora et al. 2012). Changes in macroH2A levels are also common in cancer. For example, the degree of malignancy in melanoma is inversely corre- lated with macroH2A levels, and knockdown of macroH2A increases malignancy (Kapoor et al. 2010). As macroH2A nucleosomes are more compacted, it is attractive to consider that its presence in a nucleosome reduces dynamics (Chakravarthy et al. 2005), and so its loss can promote gene misexpression. However, just what role that global changes in macroH $2 \mathrm{~A}$ levels might have in tumor progression is complicated by the evidence that different splicing isoforms produced by two different macroH2A genes are associated with very different outcomes (Sporn and Jung 2012). It is possible that these complications arise from the differential abundances of these isoforms in different cancer cell types, rather than any difference in the action of the isoforms in compacting chromatin. Interestingly, macroH2A is negatively regulated by ATRX (Ratnakumar et al. 2012), and this raises the possibility that misregulation of macroH2A contributes to the ALT phenotype.

Whereas most RI histone variants are of interest because of their potential involvement in transcriptional regulation, cenH3 nucleosomes form the foundation of the centromere in the large majority of eukaryotes, and so are crucial for genome stability (Quenet and Dalal 2012). As cenH3 mislocalization can lead to the appearance of ectopic "neocentromeres," and bridgebreakage-fusion cycles can result from a second centromere on a chromosome, overproduction of CENP-A in some cancers makes it a potential causative factor in aneuploidy (Lacoste et al. 2014; Athwal et al. 2015). Reducing CENP-A levels in cancer, for example, by targeting expression of its gene or inhibiting its incorporation into chromatin, may be a potential therapeutic strategy that would have little if any impact on nondividing cells.

\section{CONCLUDING REMARKS}

This survey of chromatin components involved in nucleosome dynamics of potential relevance to cancer underscores the intricate interrelationships between the major components, including DNA translocases, histone modifications and their reader proteins, and histone variants and their chaperones. For example, the 


\section{S. Henikoff}

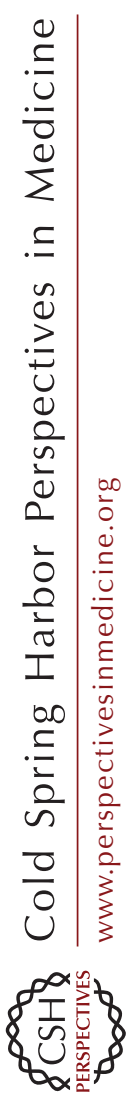

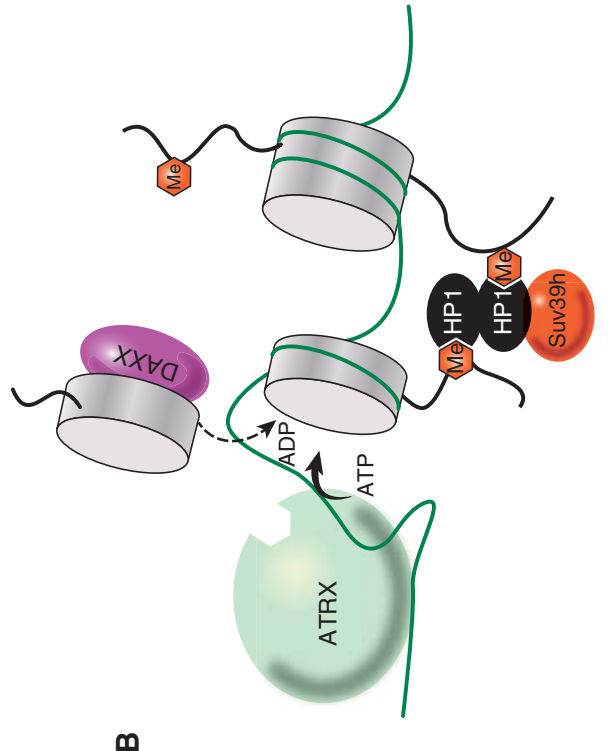

m
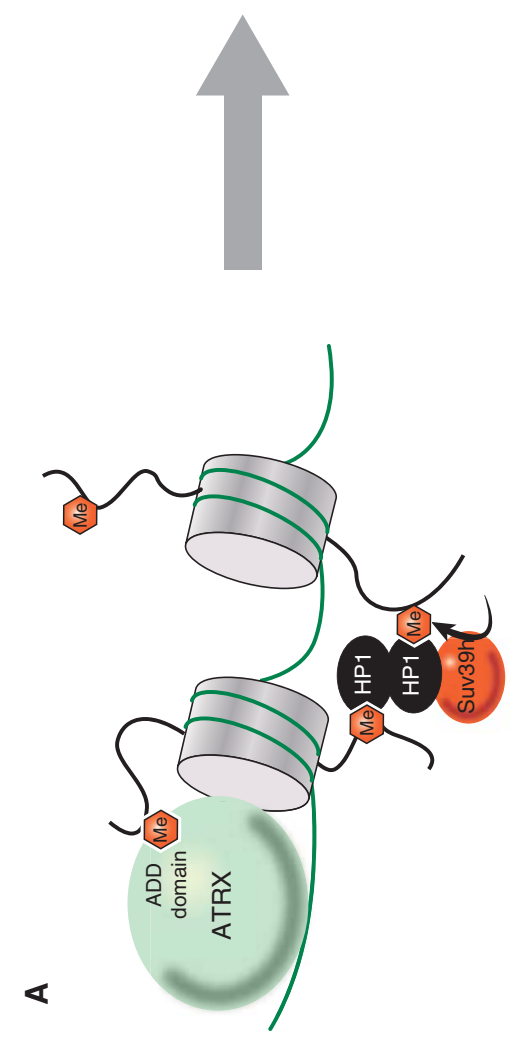

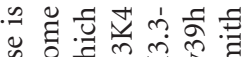

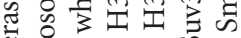

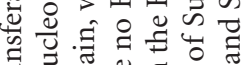

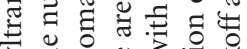
空宅

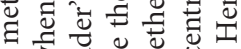
ब $3 \approx 000$

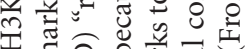
들

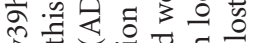

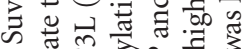

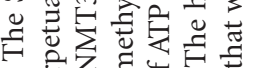
ङ 을

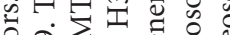
른

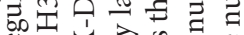

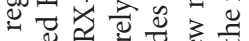

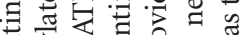

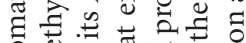

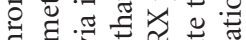

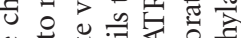

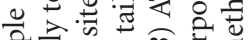

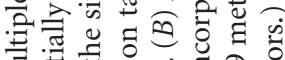

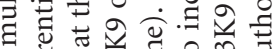
늄

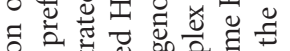

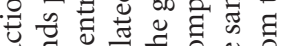

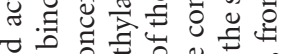
웡 0 क 는. 3 ษ $ᄋ .000$. ป

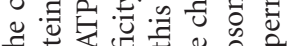

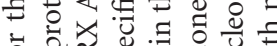

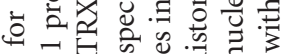

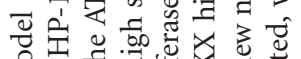

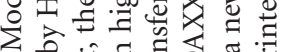

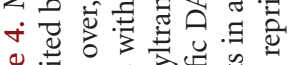

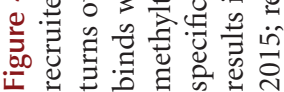


ATRX translocase, which is associated with the H3.3-specific DAXX chaperone has a dualreader module that tightly binds di- or trimethylated lysine- 9 and unmethylated lysine- 4 on the histone 3 amino-terminal tail (Fig. 4) (Eustermann et al. 2011). Teasing out these interdependencies to understand how ATRX and DAXX mutations can drive ALT or how different H3.3 mutations can drive such different tumors as aggressive DIPGs and benign chondroblastomas requires a better understanding of the dynamic processes that these components normally carry out. Increases in nucleosome dynamics can also result in genome instability, as loss of nucleosomes exposes DNA and can result in double-strand breaks (Yang et al. 2015).

In this regard, studies of model organisms have the potential of providing insight into how disruption of normal developmental processes can result in cancer. For example, an important simplification of what otherwise seems to be a byzantine network of chromatin regulators involved in tumor progression originated with fly genetics. According to the central paradigm for Drosophila development, genes are heritably maintained in the silent state in trans by the product of the Polycomb locus (Lewis 1978). This paradigm was further elaborated with the discovery of additional loci in the Polycomb group (PcGs) that maintain developmental silencing (Schwartz and Pirrotta 2013), and in the trithorax group (trxGs) that maintain gene activity (Steffen and Ringrose 2014). Although originally described for maintaining silencing and expression of "homoeotic" master regulators of the anterior-posterior morphological axis, the paradigm applies generally to maintaining developmental memory in complex animals. Biochemical studies of PcGs showed them to consist of subunits of PRC1 complexes, which act to compact chromatin (Grau et al. 2011), and of the PRC2 complex, which methylates H3K27 to heritably maintain silencing (Schwartz and Pirrotta 2013). Biochemical studies of trxGs showed them to be chromatin remodelers, histone-modifying enzymes and other chromatin regulators that are associated with gene activity (Kingston and Tamkun 2006). Upsetting the balance between trxGs and PcGs that normally regulate developmental processes in Drosophila uncovers homoeotic phenotypes. Likewise, mutations in and silencing or misexpression of mammalian orthologs of trxGs and PcGs upsets the balance between them that normally maintains developmental homeostasis. A fuller understanding of the mechanisms whereby trxGs and PcGs affect nucleosome dynamics is needed to address the question of how mutation and misregulation of these proteins can drive tumorigenesis.

\section{ACKNOWLEDGMENTS}

I thank Paul Talbert for comments on the manuscript. Work in my laboratory is supported by the Howard Hughes Medical Institute and a grant from the National Institutes of Health (R01 ES020116).

\section{REFERENCES}

* Reference is also in this collection.

Agger K, Cloos PA, Christensen J, Pasini D, Rose S, Rappsilber J, Issaeva I, Canaani E, Salcini AE, Helin K. 2007. UTX and JMJD3 are histone H3K27 demethylases involved in HOX gene regulation and development. Nature 449: $731-734$.

Allis CD, Berger SL, Cote J, Dent S, Jenuwien T, Kouzarides T, Pillus L, Reinberg D, Shi Y, Shiekhattar R, et al. 2007. New nomenclature for chromatin-modifying enzymes. Cell 131: 633-636.

Athwal RK, Walkiewicz MP, Baek S, Fu S, Bui M, Camps J, Ried T, Sung MH, Dalal Y. 2015. CENP-A nucleosomes localize to transcription factor hotspots and subtelomeric sites in human cancer cells. Epigenetics Chromatin 8: 2 .

Bao Y, Konesky K, Park YJ, Rosu S, Dyer PN, Rangasamy D, Tremethick DJ, Laybourn PJ, Luger K. 2004. Nucleosomes containing the histone variant $\mathrm{H} 2 \mathrm{~A}$.Bbd organize only 118 base pairs of DNA. EMBO J 23: 3314-3324.

Behjati S, Tarpey PS, Presneau N, Scheipl S, Pillay N, Van Loo P, Wedge DC, Cooke SL, Gundem G, Davies H, et al. 2013. Distinct H3F3A and H3F3B driver mutations define chondroblastoma and giant cell tumor of bone. Nat Genet 45: 1479-1482.

Bernt KM, Zhu N, Sinha AU, Vempati S, Faber J, Krivtsov AV, Feng Z, Punt N, Daigle A, Bullinger L, et al. 2011. MLLrearranged leukemia is dependent on aberrant $\mathrm{H} 3 \mathrm{~K} 79$ methylation by DOT1L. Cancer Cell 20: 66-78.

Bestor TH. 1996. DNA methyltransferases in mammalian development and genome defense. In Epigenetic mechanisms of gene regulation (ed. Russo VEA, Martienssen RA, Riggs AD), pp. 61-76. Cold Spring Harbor Laboratory Press, Cold Spring Harbor, NY. 


\section{S. Henikoff}

Canzio D, Chang EY, Shankar S, Kuchenbecker KM, Simon MD, Madhani HD, Narlikar GJ, Al-Sady B. 2011. Chromodomain-mediated oligomerization of HP1 suggests a nucleosome-bridging mechanism for heterochromatin assembly. Mol Cell 41: 67-81.

* Carlson SM, Gozani O. 2016. Non-histone lysine methylation in the regulation of cancer pathways. Cold Spring Harb Perpect Med doi: 10.1101/cshperspect.a026435.

Carlson SM, Moore KE, Sankaran SM, Reynoird N, Elias JE Gozani O. 2015. A proteomic strategy identifies lysine methylation of splicing factor snRNP70 by the SETMAR enzyme. J Biol Chem 290: 12040-12047.

Chaban Y, Ezeokonkwo C, Chung WH, Zhang F, Kornberg RD, Maier-Davis B, Lorch Y, Asturias FJ. 2008. Structure of a RSC-nucleosome complex and insights into chromatin remodeling. Nat Struct Mol Biol 15: 1272-1277.

Chakravarthy S, Gundimella SK, Caron C, Perche PY, Pehrson JR, Khochbin S, Luger K. 2005. Structural characterization of the histone variant macroH2A. Mol Cell Biol 25: 7616-7624.

Chang FT, Chan FL, JD RM, Udugama M, Mayne L, Collas P, Mann JR, Wong LH. 2015. CHK1-driven histone H3.3 serine 31 phosphorylation is important for chromatin maintenance and cell survival in human ALT cancer cells. Nucleic Acids Res 43: 2603-2614.

Chen X, Cui D, Papusha A, Zhang X, Chu CD, Tang J, Chen K, Pan X, Ira G. 2012. The Fun30 nucleosome remodeller promotes resection of DNA double-strand break ends. Nature 489: 576-580.

Clapier CR, Cairns BR. 2009. The biology of chromatin remodeling complexes. Annu Rev Biochem 78: 273-304.

Colon-Bolea P, Crespo P. 2014. Lysine methylation in cancer: SMYD3-MAP3K2 teaches us new lessons in the Ras-ERK pathway. Bioessays 36: 1162-1169.

Copeland RA, Olhava EJ, Scott MP. 2010. Targeting epigenetic enzymes for drug discovery. Curr Opin Chem Biol 14: 505-510.

Costanzi C, Pehrson JR. 1998. Histone macroH2A1 is concentrated in the inactive $\mathrm{X}$ chromosome of female mammals. Nature 393: 599-601.

Costelloe T, Louge R, Tomimatsu N, Mukherjee B, Martini E, Khadaroo B, Dubois K, Wiegant WW, Thierry A, Burma S, et al. 2012. The yeast Fun30 and human SMARCAD1 chromatin remodellers promote DNA end resection. Nature 489: 581-584.

Daigle SR, Olhava EJ, Therkelsen CA, Majer CR, Sneeringer CJ, Song J, Johnston LD, Scott MP, Smith JJ, Xiao Y, et al. 2011. Selective killing of mixed lineage leukemia cells by a potent small-molecule DOT1L inhibitor. Cancer Cell 20: $53-65$.

Dion M, Kaplan T, Friedman N, Rando OJ. 2007. Dynamics of replication-independent histone turnover in budding yeast. Science 315: 1405-1408.

Downey M, Baetz K. 2015. Building a KATalogue of acetyllysine targeting and function. Brief Funct Genomics 15: 109-118.

Drane P, Ouararhni K, Depaux A, Shuaib M, Hamiche A. 2010. The death-associated protein DAXX is a novel histone chaperone involved in the replication-independent deposition of H3.3. Genes Dev 24: 1253-1265.
Eastlund A, Malik SS, Fischer CJ. 2013. Kinetic mechanism of DNA translocation by the RSC molecular motor. Arch Biochem Biophys 532: 73-83.

Elsasser SJ, Huang H, Lewis PW, Chin JW, Allis CD, Patel DJ. 2012. DAXX envelops a histone $\mathrm{H} 3.3-\mathrm{H} 4$ dimer for H3.3specific recognition. Nature 491: 560-565.

Eustermann S, Yang JC, Law MJ, Amos R, Chapman LM, Jelinska C, Garrick D, Clynes D, Gibbons RJ, Rhodes D, et al. 2011. Combinatorial readout of histone H3 modifications specifies localization of ATRX to heterochromatin. Nat Struct Mol Biol 18: 777-782.

Filippakopoulos P, Qi J, Picaud S, Shen Y, Smith WB, Fedorov O, Morse EM, Keates T, Hickman TT, Felletar I, et al. 2010. Selective inhibition of BET bromodomains. Nature 468: 1067-1073.

Flynn RL, Cox KE, Jeitany M, Wakimoto H, Bryll AR, Ganem NJ, Bersani F, Pineda JR, Suva ML, Benes CH, et al. 2015. Alternative lengthening of telomeres renders cancer cells hypersensitive to ATR inhibitors. Science 347: 273277.

Funato K, Major T, Lewis PW, Allis CD, Tabar V. 2014. Use of human embryonic stem cells to model pediatric gliomas with H3.3K27M histone mutation. Science 346: 15291533.

Ganguli D, Chereji RV, Iben JR, Cole HA, Clark DJ. 2014. RSC-dependent constructive and destructive interference between opposing arrays of phased nucleosomes in yeast. Genome Res 24: 1637-1649.

Gaydos LJ, Wang W, Strome S. 2014. Gene repression. H3K27me and PRC2 transmit a memory of repression across generations and during development. Science 345: $1515-1518$.

Grau DJ, Chapman BA, Garlick JD, Borowsky M, Francis NJ, Kingston RE. 2011. Compaction of chromatin by diverse Polycomb group proteins requires localized regions of high charge. Genes Dev 25: 2210-2221.

Hargreaves DC, Crabtree GR. 2011. ATP-dependent chromatin remodeling: Genetics, genomics and mechanisms. Cell Res 21: 396-420.

Hartley PD, Madhani HD. 2009. Mechanisms that specify promoter nucleosome location and identity. Cell 137: $445-458$.

Heaphy CM, de Wilde RF, Jiao Y, Klein AP, Edil BH, Shi C, Bettegowda C, Rodriguez FJ, Eberhart CG, Hebbar S, et al. 2011a. Altered telomeres in tumors with ATRX and DAXX mutations. Science 333: 425.

Heaphy CM, Subhawong AP, Hong SM, Goggins MG, Montgomery EA, Gabrielson E, Netto GJ, Epstein JI, Lo$\tan$ TL, Westra WH, et al. 2011b. Prevalence of the alternative lengthening of telomeres telomere maintenance mechanism in human cancer subtypes. Am J Pathol 179: $1608-1615$.

Henikoff S, Shilatifard A. 2011. Histone modification: Cause or cog? Trends Genet 27: 389-396.

Henikoff S, Smith MM. 2015. Histone variants and epigenetics. Cold Spring Harb Perspect Biol 7: a019364.

Herz HM, Morgan M, Gao X, Jackson J, Rickels R, Swanson SK, Florens L, Washburn MP, Eissenberg JC, Shilatifard A. 2014. Histone H3 lysine-to-methionine mutants as a paradigm to study chromatin signaling. Science 345 : 1065-1070. 
Hinz JM, Czaja W. 2015. Facilitation of base excision repair by chromatin remodeling. DNA Repair (Amst) 36: 91-97.

Hua S, Kallen CB, Dhar R, Baquero MT, Mason CE, Russel BA, Shah PK, Liu J, Khramtsov A, Tretiakova MS, et al. 2008. Genomic analysis of estrogen cascade reveals histone variant H2A.Z associated with breast cancer progression. Mol Syst Biol 4: 188.

Jiao L, Liu X. 2015. Structural basis of histone H3K27 trimethylation by an active Polycomb repressive complex 2 . Science 350: aac4383.

Jiao Y, Shi C, Edil BH, de Wilde RF, Klimstra DS, Maitra A, Schulick RD, Tang LH, Wolfgang CL, Choti MA, et al. 2011. DAXX/ATRX, MEN1, and mTOR pathway genes are frequently altered in pancreatic neuroendocrine tumors. Science 331: 1199-1203.

Kadoch C, Hargreaves DC, Hodges C, Elias L, Ho L, Ranish J, Crabtree GR. 2013. Proteomic and bioinformatic analysis of mammalian SWI/SNF complexes identifies extensive roles in human malignancy. Nat Genet 45: 592-601.

Kapoor A, Goldberg MS, Cumberland LK, Ratnakumar K, Segura MF, Emanuel PO, Menendez S, Vardabasso C, Leroy G, Vidal CI, et al. 2010. The histone variant macroH2A suppresses melanoma progression through regulation of CDK8. Nature 468: 1105-1109.

Kim KH, Roberts CW. 2014. Mechanisms by which SMARCB1 loss drives rhabdoid tumor growth. Cancer Genet 207: 365-372.

Kingston RE, Tamkun J. 2014. Transcriptional regulation by trithorax-group proteins. Cold Spring Harb Perspect Biol 6: 019349

Koppens M, van Lohuizen M. 2015. Context-dependent actions of Polycomb repressors in cancer. Oncogene 17: 1341-1352.

Lacoste N, Woolfe A, Tachiwana H, Garea AV, Barth T, Cantaloube S, Kurumizaka H, Imhof A, Almouzni G. 2014 Mislocalization of the centromeric histone variant CenH3/CENP-A in human cells depends on the chaperone DAXX. Mol Cell 53: 631-644.

Lai F, Shiekhattar R. 2014. Enhancer RNAs: The new molecules of transcription. Curr Opin Genet Dev 25: 38-42.

Laufer BI, Singh SM. 2015. Strategies for precision modulation of gene expression by epigenome editing: An overview. Epigenetics Chromatin 8: 34.

Law MJ, Lower KM, Voon HP, Hughes JR, Garrick D, Viprakasit V, Mitson M, De Gobbi M, Marra M, Morris A, et al. 2010. ATR-X syndrome protein targets tandem repeats and influences allele-specific expression in a sizedependent manner. Cell 143: 367-378.

Lee HG, Kahn TG, Simcox A, Schwartz YB, Pirrotta V. 2015. Genome-wide activities of polycomb complexes control pervasive transcription. Genome Res 25: 1170-1181.

Levy D, Liu CL, Yang Z, Newman AM, Alizadeh AA, Utz PJ, Gozani O. 2011. A proteomic approach for the identification of novel lysine methyltransferase substrates. Epigenetics Chromatin 4: 19.

Lewis EB. 1978. A gene complex controlling segmentation in Drosophila. Nature 276: 565-570.

Lewis PW, Elsaesser SJ, Noh KM, Stadler SC, Allis CD. 2010. Daxx is an H3.3-specific histone chaperone and cooperates with ATRX in replication-independent chromatin
Mechanisms of Nucleosome Dynamics In Vivo

assembly at telomeres. Proc Natl Acad Sci 107: 1407514080 .

Lewis PW, Muller MM, Koletsky MS, Cordero F, Lin S, Banaszynski LA, Garcia BA, Muir TW, Becher OJ, Allis CD. 2013. Inhibition of PRC2 activity by a gain-of-function H3 mutation found in pediatric glioblastoma. Science 340: $857-861$.

Li S. 2015. Transcription coupled nucleotide excision repair in the yeast Saccharomyces cerevisiae: The ambiguous role of Rad26. DNA Repair (Amst) 36: 43-48.

Liu Z, Lavis LD, Betzig E. 2015. Imaging live-cell dynamics and structure at the single-molecule level. Mol Cell 58: 644-659.

Lorch Y, Maier-Davis B, Kornberg RD. 2006. Chromatin remodeling by nucleosome disassembly in vitro. Proc Natl Acad Sci 103: 3090-3093.

Lorch Y, Maier-Davis B, Kornberg RD. 2010. Mechanism of chromatin remodeling. Proc Natl Acad Sci 107: 34583462 .

Lovejoy CA, Li W, Reisenweber S, Thongthip S, Bruno J, de Lange T, De S, Petrini JH, Sung PA, Jasin M, et al. 2012. Loss of ATRX, genome instability, and an altered DNA damage response are hallmarks of the alternative lengthening of telomeres pathway. PLoS Genet 8: e1002772.

Lu C, Jain SU, Hoelper D, Bechet D, Molden RC, Ran L, Murphy D, Venneti S, Hameed M, Pawel BR, et al. 2016. Histone H3K36 mutations promote sarcomagenesis through altered histone methylation landscape. Science 352: $844-849$.

Ma N, Luo Y, Wang Y, Liao C, Ye WC, Jiang S. 2016. Selective histone deacetylase inhibitors with anticancer activity. Curr Top Med Chem 16: 415-426.

Marzluff WF, Gongidi P, Woods KR, Jin J, Maltais LJ. 2002. The human and mouse replication-dependent histone genes. Genomics 80: 487-498.

McBrian MA, Behbahan IS, Ferrari R, Su T, Huang TW, Li K, Hong CS, Christofk HR, Vogelauer M, Seligson DB, et al. 2013. Histone acetylation regulates intracellular pH. Mol Cell 49: 310-321.

Morishita M, Mevius D, di Luccio E. 2014. In vitro histone lysine methylation by NSD1, NSD2/MMSET/WHSC1 and NSD3/WHSC1L. BMC Struct Biol 14: 25.

Picketts DJ, Higgs DR, Bachoo S, Blake DJ, Quarrell OW, Gibbons RJ. 1996. ATRX encodes a novel member of the SNF2 family of proteins: Mutations point to a common mechanism underlying the ATR-X syndrome. Hum Mol Genet 5: 1899-1907.

Pon JR, Marra MA. 2015. Driver and passenger mutations in cancer. Annu Rev Pathol 10: 25-50.

Popovic R, Martinez-Garcia E, Giannopoulou EG, Zhang Q, Zhang Q, Ezponda T, Shah MY, Zheng Y, Will CM, Small EC, et al. 2014. Histone methyltransferase MMSET/ NSD2 alters EZH2 binding and reprograms the myeloma epigenome through global and focal changes in H3K36 and H3K27 methylation. PLoS Genet 10: e1004566.

Ptashne M. 2007. On the use of the word "epigenetic." Curr Biol 17: R233-R236.

Quenet D, Dalal Y. 2012. The CENP-A nucleosome: A dynamic structure and role at the centromere. Chromosome Res 20: 465-479. 


\section{S. Henikoff}

Ramachandran S, Henikoff S. 2015. Replicating nucleosomes. Sci Adv 1: e1500587.

Ramachandran S, Zentner GE, Henikoff S. 2015. Asymmetric nucleosomes flank promoters in the budding yeast genome. Genome Res 25: 381-390.

Ratnakumar K, Duarte LF, LeRoy G, Hasson D, Smeets D, Vardabasso C, Bonisch C, Zeng T, Xiang B, Zhang DY, et al. 2012. ATRX-mediated chromatin association of histone variant macroH2 $\mathrm{A} 1$ regulates $\alpha$-globin expression. Genes Dev 26: 433-438.

Ray-Gallet D, Quivy J-P, Scamps C, Martini EM, Lipinski M, Almouzni G. 2002. HIRA is critical for a nucleosome assembly pathway independent of DNA synthesis. Mol Cell 9: 1091-1100.

Riedel SS, Neff T, Bernt KM. 2015. Histone profiles in cancer. Pharmacol Ther 154: 87-109.

Schneiderman JI, Sakai A, Goldstein S, Ahmad K. 2009. The XNP remodeler targets dynamic chromatin in Drosophila. Proc Natl Acad Sci 106: 14472-14477.

Schneiderman JI, Orsi GA, Hughes KT, Loppin B, Ahmad K. 2012. Nucleosome-depleted chromatin gaps recruit assembly factors for the H3.3 histone variant. Proc Nat Acad Sci 109: 19721-19726.

Schotta G, Ebert A, Krauss V, Fischer A, Hoffmann J, Rea S, Jenuwein T, Dorn R, Reuter G. 2002. Central role of Drosophila $\mathrm{SU}(\mathrm{VAR}) 3-9$ in histone $\mathrm{H} 3-\mathrm{K} 9$ methylation and heterochromatic gene silencing. EMBO J 21: 1121-1131.

Schwartz YB, Pirrotta V. 2013. A new world of polycombs: Unexpected partnerships and emerging functions. Nat Rev Genet 14: 853-864.

Shi J, Vakoc CR. 2014. The mechanisms behind the therapeutic activity of BET bromodomain inhibition. Mol Cell 54: 728-736.

Sporn JC, Jung B. 2012. Differential regulation and predictive potential of MacroH2A1 isoforms in colon cancer Am J Pathol 180: 2516-2526.

Steffen PA, Ringrose L. 2014. What are memories made of? How polycomb and trithorax proteins mediate epigenetic memory. Nat Rev Mol Cell Biol 15: 340-356.

Suto RK, Clarkson MJ, Tremethick DJ, Luger K. 2000. Crystal structure of a nucleosome core particle containing the variant histone H2A.Z. Nat Struct Biol 7: 1121-1124.

Tamkun JW, Deuring R, Scott MP, Kissinger M, Pattatucci AM, Kaufman TC, Kennison JA. 1992. brahma: A regulator of Drosophila homeotic genes structurally related to the yeast transcriptional activator SNF2/SWI2. Cell 68: 561-572.

Teves SS, Weber CM, Henikoff S. 2014. Transcribing through the nucleosome. Trends Biochem Sci 39: 577-586.

Valdes-Mora F, Song JZ, Statham AL, Strbenac D, Robinson MD, Nair SS, Patterson KI, Tremethick DJ, Stirzaker C,
Clark SJ. 2012. Acetylation of H2A.Z is a key epigenetic modification associated with gene deregulation and epigenetic remodeling in cancer. Genome Res 22: 307-321.

Vogelstein B, Papadopoulos N, Velculescu VE, Zhou S, Diaz LA Jr, Kinzler KW. 2013. Cancer genome landscapes. Science 339: 1546-1558.

Watanabe S, Peterson CL. 2010. The INO80 family of chromatin-remodeling enzymes: Regulators of histone variant dynamics. Cold Spring Harb Symp Quant Biol 75: $35-42$.

Watanabe S, Radman-Livaja M, Rando OJ, Peterson CL. 2013. A histone acetylation switch regulates H2A.Z deposition by the SWR-C remodeling enzyme. Science 340: 195-199.

Waterborg JH. 1993. Histone synthesis and turnover in alfalfa. Fast loss of highly acetylated replacement histone variant H3.2. J Biol Chem 268: 4912-4917.

Waterborg JH. 2002. Dynamics of histone acetylation in vivo. A function for acetylation turnover? Biochem Cell Biol 80: 363-378.

Waters R, van Eijk P, Reed S. 2015. Histone modification and chromatin remodeling during NER. DNA Repair (Amst) 36: $105-113$.

Weintraub H, Groudine M. 1976. Chromosomal subunits in active genes have an altered conformation. Science 193: 848-856.

Wen H, Li Y, Xi Y, Jiang S, Stratton S, Peng D, Tanaka K, Ren Y, Xia Z, Wu J, et al. 2014. ZMYND11 links histone H3.3K36me3 to transcription elongation and tumour suppression. Nature 508: 263-268.

Wilson BG, Roberts CW. 2011. SWI/SNF nucleosome remodellers and cancer. Nat Rev Cancer 11: 481-492.

Wolffe AP. 1992. Chromatin: Structure and function. Academic, San Diego.

Wollmann P, Cui S, Viswanathan R, Berninghausen O, Wells MN, Moldt M, Witte G, Butryn A, Wendler P, Beckmann $\mathrm{R}$, et al. 2011. Structure and mechanism of the Swi2/Snf2 remodeller Mot1 in complex with its substrate TBP. $\mathrm{Na}$ ture 475: 403-407.

Wu G, Broniscer A, McEachron TA, Lu C, Paugh BS, Becksfort J, Qu C, Ding L, Huether R, Parker M, et al. 2012. Somatic histone $\mathrm{H} 3$ alterations in pediatric diffuse intrinsic pontine gliomas and non-brainstem glioblastomas. Nat Genet 44: 251-253.

Yang F, Kemp CJ, Henikoff S. 2015. Anthracyclines induce double-strand DNA breaks at active gene promoters. $\mathrm{Mu}$ tat Res 773: 9-15.

Zentner GE, Henikoff S. 2013. Mot1 redistributes TBP from TATA-containing to TATA-less promoters. Mol Cell Biol 33: 4996-5004. 


\title{
$\&_{\mathrm{CSH}}^{\infty} \&$ Cold Spring Harbor

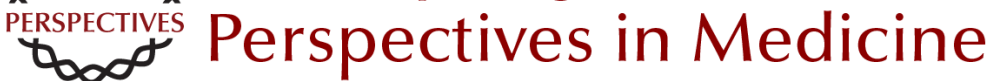

\section{Mechanisms of Nucleosome Dynamics In Vivo}

\author{
Steven Henikoff
}

Cold Spring Harb Perspect Med 2016; doi: 10.1101/cshperspect.a026666 originally published online August 8, 2016

\section{Subject Collection Chromatin Deregulation in Cancer}

\section{Mixed-Lineage Leukemia Fusions and Chromatin in Leukemia \\ Andrei V. Krivtsov, Takayuki Hoshii and Scott A. Armstrong}

Targeting Cancer Cells with BET Bromodomain Inhibitors

Yali Xu and Christopher R. Vakoc

The Role of Nuclear Receptor-Binding SET Domain Family Histone Lysine Methyltransferases in Cancer

Richard L. Bennett, Alok Swaroop, Catalina Troche, et al.

SETting the Stage for Cancer Development:

SETD2 and the Consequences of Lost Methylation Catherine C. Fahey and lan J. Davis

ATRX and DAXX: Mechanisms and Mutations Michael A. Dyer, Zulekha A. Qadeer, David Valle-Garcia, et al.

DNMT3A in Leukemia

Lorenzo Brunetti, Michael C. Gundry and Margaret A. Goodell

Oncogenic Mechanisms of Histone H3 Mutations Daniel N. Weinberg, C. David Allis and Chao Lu

Nonhistone Lysine Methylation in the Regulation of Cancer Pathways

Scott M. Carlson and Or Gozani
TET2 in Normal and Malignant Hematopoiesis Robert L. Bowman and Ross L. Levine

Long Noncoding RNAs: At the Intersection of Cancer and Chromatin Biology Adam M. Schmitt and Howard Y. Chang

DNA Hypomethylating Drugs in Cancer Therapy Takahiro Sato, Jean-Pierre J. Issa and Patricia Kropf

The Chromodomain Helicase DNA-Binding Chromatin Remodelers: Family Traits that Protect from and Promote Cancer Alea A. Mills

Exploitation of EP300 and CREBBP Lysine Acetyltransferases by Cancer Narsis Attar and Siavash K. Kurdistani

Histone Lysine Demethylase Inhibitors Ashwini Jambhekar, Jamie N. Anastas and Yang Shi

Cohesin Mutations in Cancer Magali De Koninck and Ana Losada

MLL3/MLL4/COMPASS Family on Epigenetic Regulation of Enhancer Function and Cancer Christie C. Sze and Ali Shilatifard

For additional articles in this collection, see http://perspectivesinmedicine.cshlp.org/cgi/collection/ 